\title{
An evaluation of the impact of e-Portfolio supported pedagogic processes on students' reflective capacity
}

\author{
Sarah Wilson-Medhurst \\ Coventry University, UK \\ Andrew Turner \\ Coventry University, UK
}

\begin{abstract}
This paper describes research evaluating pedagogical strategies and processes that develop the reflective capacity of students. An Appreciative Inquiry framework was adopted to establish, from a student perspective, what works or 'gives life' in terms of supporting and encouraging a reflective capacity. The context was an undergraduate module with an explicit focus on employability and 'transition-out' of university. Students were drawn from a range of courses as diverse as Performing Arts, Business Management, Engineering and Computing Science. This presented both challenges and benefits. The module utilised an e-Portfolio tool (PebblePad) linked to formative and summative assessment to support students in their learning development, including reflection around personal and career development. Key elements of the module which developed the reflective capacity of students, evident in appreciative feedback, were a personal statement first assignment linked to interdisciplinary group work and activities which scaffold the reflective process. The paper discusses the pedagogical processes involved and highlights areas for further research.
\end{abstract}

Key words: reflection; PDP; employability; e-Portfolio; assessment for learning; Appreciative Inquiry.

\section{Introduction}

The authors are two researcher practitioners who are members of the NTFS National Action Research Network (NARN) Project on researching and evaluating Personal 
Development Planning and e-Portfolio practice (http://www.bolton.ac.uk/EDU/HEA NTFSNARNProject/Home.aspx). Personal Development Planning (PDP) is defined as 'a structured and supported process undertaken by an individual to reflect upon their own learning, performance and/or achievement and to plan for their personal, educational and career development' (QAA, 2001, p.2). All UK Higher Education Institutions (HEIs) are required to offer opportunities to students to engage in this process. The outcomes of the PDP process are a transcript which is the formal record of the outcomes of the student's HE experience, and a personal development portfolio product which encompasses the records and claims for learning that underlie the PDP process. There has been a movement toward the use of electronic portfolio platforms to support PDP production (Strivens, 2007).

This research emanates from earlier work by the researchers as outlined in WilsonMedhurst (2005a; 2005b) and from strategic curriculum interventions around employability at Coventry University. It is also informed by a body of literature around the value of ePortfolio and PDP processes in supporting student development (for example, Stefani et al., 2007; Orsini-Jones and Jones, 2007). In particular, research by Brennan and Shah (2003) highlights confidence as an important determinant of students' success (or otherwise) in securing employment or other graduate destination at the end of their degree, as well as the need to provide equality of access to resources and processes that will support this confidence building. This fits well with notions of self-efficacy (Bandura, 1997) flagged in the USEM (Understanding, Skills or skilful practices, Efficacy beliefs, and Meta-cognition) model of employability, which also highlights meta-cognition or a reflective capacity as an important component of employability (Yorke et al., 2003) that can be supported through the PDP process.

The USEM model is depicted in Figure 1 (Yorke et al., 2003, p.5). In the USEM model, 'the 'E' component suffuses the other contributions to employability' (Yorke et al., 2003, p.5) but the other components, including meta-cognition, interact in the 'production' of employability and citizenship. 


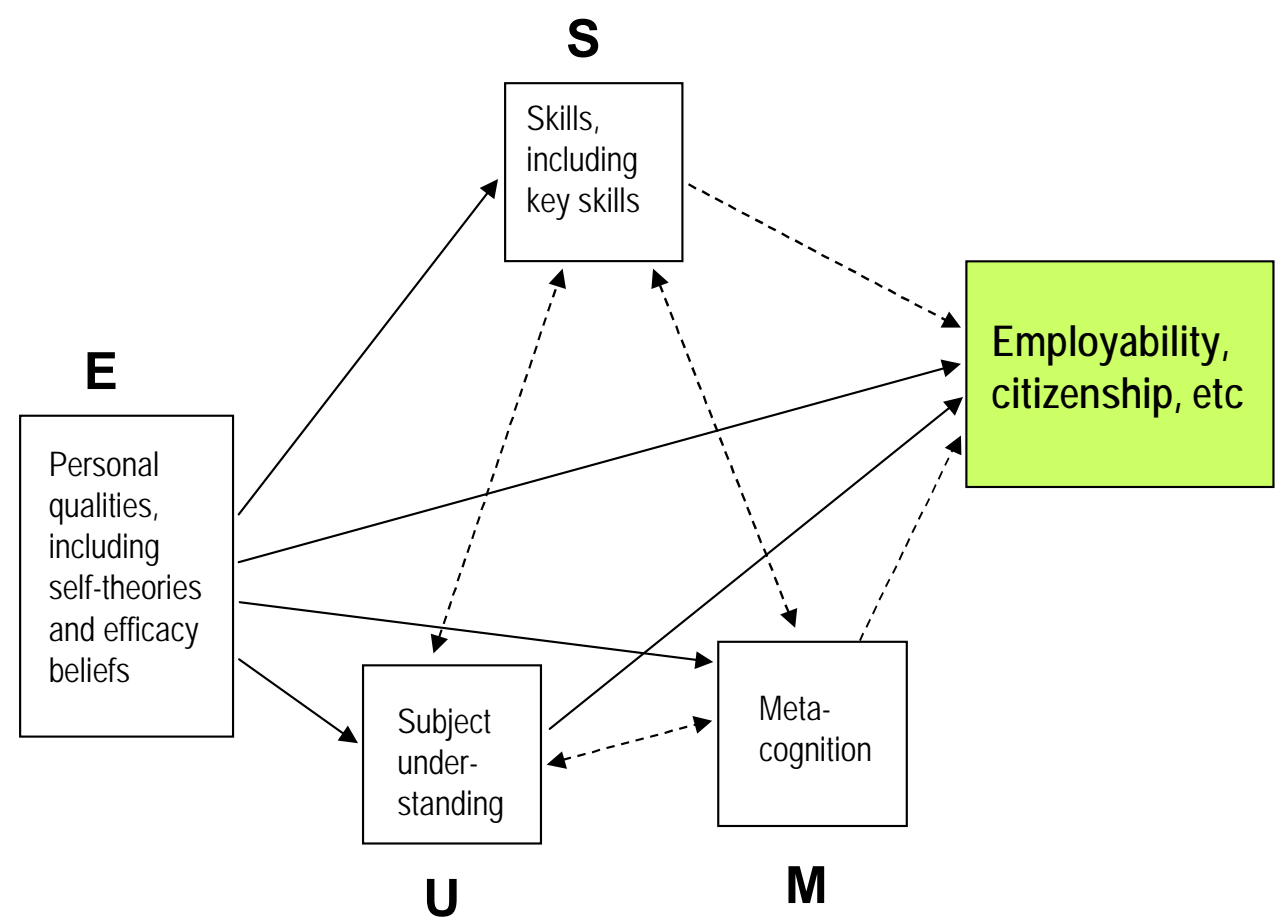

Figure 1. The USEM model (Yorke et al., 2003, p.5).

\section{Coventry response}

A key feature of Coventry University's response to supporting undergraduates to develop their employability and PDP has been the introduction of the Add+vantage suite of modules. With the exception of accredited health courses, all students must choose one Add+vantage module each year to study as part of their course. They count towards the total number of credits required for a student's degree in the same way that the other course modules do and must be passed in order for a student to progress and receive their final award. There are a total of around 60 Add+vantage modules at each level of study which develop a diverse range of skills, knowledge or attributes. A common element running through all the modules is a self-directed but assessed element which is designed to develop employability competencies. More details of the Add+vantage scheme can be found at http://wwwm.coventry.ac.uk/careers/Addvantage/Pages/scheme.aspx.

This research focuses on a level 3 undergraduate Add+vantage module where the PDP process has an explicit focus on employability and 'transition-out' of university (into 
employment, post-graduate study or other graduate destination). Eighty five students (two intakes) studied the module in 2008/9, and forty eight (one intake) in 2009/10 drawn from a range of courses as diverse as Performing Arts, Business Management, Engineering and Computing Science, which presented both challenges in meeting their needs and benefits through the interaction between such a diverse group of learners.

The module utilises an e-Portfolio tool (PebblePad) linked to formative and summative assessment to support students in their learning development, including reflection around personal and career development. Reflection, the role it plays in student learning and how it can be supported is likely to be a key focus for the next generation of electronic portfolio research (Yancey, 2009) who also observes 'many colleges and universities, including Sheffield Hallam University, the University of Waterloo, and Alverno College, have also found that helping students develop a 'capacity to reflect' is a critical educational outcome, in and of itself' (Yancey, 2009, p.5). Citing Penny-Light et al:

Reflection is a learned skill. Students do not necessarily 'know' how to reflect effectively on their learning and use those reflections to make connections between the learning that occurs in different contexts (academic, workplace, community). This indicates that we need to carefully scaffold opportunities for reflection into academic programs for students so that they have time to develop this ability. (Penny-Light et al., cited Yancey, 2009, p.6).

This also presents challenges to the academic who may see supporting such development, especially in relation to employability, as a blurring of practice boundaries between themselves and other professional staff, such as those in careers.

Our research question therefore was:

What are the elements that support and encourage a reflective capacity in students?

In this research context, the module assignments provide the key challenges that aim to stimulate students' reflection around personal and career development. Thus the elements in the above research question include these assignments as well as the assignment marking criteria, the e-Portfolio support tool, group and self-evaluation activities. These elements provide for the structured and supported process of PDP. 
The elements chosen reflected an intention to support students in meeting the following learning outcomes of the module:

1. Reflect upon their employability competencies and career management skills, and plan for their future development.

2. Critically reflect upon their personal and professional development within their undergraduate studies and wider experiences.

3. Identify, analyse and evidence the personal capabilities and attributes that will be important to relevant employer, professional body and/or postgraduate requirements.

4. Plan to support their transition from university and achievement of their chosen graduate destination or activity.

5. Appreciate the links between personal development planning at university and continuing professional development.

In outline, the key elements and associated pedagogical strategies were:

- A self-reflective personal statement assignment submitted part-way through the module.

o A linking interdisciplinary group work activity with a peer-to-peer formative feedback point.

- Self-assessment activities including relating to the career choice processes of: accurate self-appraisal; gathering occupational information; goal selection; making plans for the future; and problem solving (Crites, 1976; 1978).

- Scaffolding questions: Where am I now? Where do I want to be? Where do I need to be? How will I get there? (Kumar, 2007).

- Self-assessment of personal statement submission against assignment marking criteria (before tutor feedback and mark returned).

- A personal action plan assignment submitted at the end of the module.

- E-portfolio scaffolding, particularly for assembling and presenting evidence related to the personal statement and action planning assignments.

- Activity-led learning approach (Wilson-Medhurst, 2008) for key parts of the delivery. 


\section{Defining reflection}

Reflection and reflective writing (as one way of 'evidencing' reflection) require explanation in order for students to understand what is required of them (Wilson-Medhurst, 2005b), especially since there are various definitions of reflection according to the different background theories of reflection (Andrew et al., 2002; Ada, 2010). In this module, students are introduced to reflection by way of Kolb's learning cycle (Kolb, 1984) and then through Moon's, 'the presentation' reflective writing example (Moon, 2001). In this way they are introduced to a 'common sense' view of reflection i.e. that it is:

... a form of mental processing with a purpose and/or an anticipated outcome that is applied to relatively complicated or unstructured ideas for which there is not an obvious solution. (Moon, 1999, p.4)

There is an outcome to the process (Moon, 1999). Also that:

Reflection lies somewhere around the notion of learning and thinking. We reflect in order to learn something, or we learn as a result of reflecting. (Moon, cited WilsonMedhurst, 2005b, p.91)

As it is an internal mental process, we can't 'see' reflection. The evidence (or otherwise) for reflection comes from the students' outputs, such as their behaviours and self-reports. Here reflection is within the context of employability and personal development planning for 'transition out' of university.

As reflection is a personal process, the researchers' aim was to find out, from the learner perspective, what aspects or elements 'give life' in terms of this module and what this tells us about the elements that support and encourage a reflective capacity. That is, the evidence comes from the students' own feedback on the process they have taken part in and the elements they have engaged with.

Linking back to the USEM model (Yorke et al., 2003) this module asks students to reflect upon their development - the skills or skilful practices, understandings (of the subject and of themselves) and their own personal qualities that they have developed. This reflection is within the context of a target graduate destination that they have chosen. The reflection is 
therefore focussed around a specific purpose (Moon, 1999) i.e. career decision making and related career choice processes. In students' commentary and feedback on the process they have undertaken, the researchers are therefore looking for evidence of an outcome i.e. that something has been learnt, that thinking has shifted or an affective change, and what this might tell us about the elements and processes the student has engaged with.

\section{Methodology}

For this research we used an Appreciative Inquiry (AI) (Cooperrider et al., 2008) framework. Al looks for what is working well (rather than problems) and assumes that whatever it is you would like more of, it is already in situ in one form or another - you therefore need to find it and then develop it. In its full or pure form Al has four 'D' phases: Discovery (What gives life? or the best of what is); Dream (What might be?); Design (How can it be?); Destiny (What will be?) (Cooperrider et al., 2008). As Cousins, 2009 observes Al can be viewed as a 'spirit of inquiry' rather than a 'pure' methodology and the researchers took the same view and adapted Al to meet this investigation's requirements.

Hence, an Al framework was adopted to establish, from a student perspective, what works or 'gives life' in terms of supporting and encouraging a reflective capacity. This effectively constitutes the 'discovery' phase of the full Al methodology. Our aim was to complete the discovery phase, so that for future iterations of the module we would have a better basis to 'dream' how we might best use the supporting elements to encourage a reflective capacity, and 'design' what would work and how.

For this research then, at a key point during the module students were asked to comment on what had worked and things they would develop or improve further in the light of their experience. The questions were:

- What did you think is the thing you did best in [personal statement] assignment 1 ?

- How could you improve your assignment 1 submission?

- What was the most useful thing you learned while doing this assignment 1 ?

- Where do you think this will come in useful next?

- Finally, what has been the most useful aspect of the module so far? And why? 
The feedback was captured as written submissions managed through the electronic portfolio environment. In addition there were other various self-assessment and reflection points during the module which again were captured within the electronic portfolio environment.

These reflection points were built into the module and were designed to support students in getting the most out of the module, including planning for the next activity. They also served as a source of data on what works from the student perspective. The written submissions were thematically analysed with the aid of the qualitative data analysis software, AtlasTi.

\section{Findings}

The findings are drawn from an analysis of the students written answers to the above five key questions after they were over half way through the module and had submitted the first assignment (a self-reflective personal statement) and had self-assessed their submission against the assessment criteria for the assignment. As part of the module design they had not yet received the tutor's feedback (and mark) at this point.

For many students there was clear evidence of a self-development outcome, indicating that the students perceived that they had developed their capacity to identify their developments and an understanding of the skills that they had developed. This is reflected in the following sample quotes from students (students typed their responses within the ePortfolio environment and were not asked to spell check their responses. Minor slips on the keyboard are left as written, as are spelling errors):

I now feel comfortable with my strengths and weaknesses, which was used, using self-assessment. I feel that I can reflect and critically analyse areas for development and improvement in relation to a career in the graduate market.

A greater understanding of my own skills and the way I have developed in my time at university. 
Analysing myself more and learning more about myself in terms of reflection has been really interesting and a unique experience, this has been the most useful part of the module so far.

The most useful aspect of this module so far is the fact that it has enabled me to realise what skills I have and what I have developed during my time at University. This, I believe, will help me immensely as I am going on to further education next year, and I have all the information now to aid me with this.

The above feedback was evidence that students were beginning to surface the development of skills and attributes at university which had previously been implicit within their studies. Such an understanding of the skills and skilful practices and understandings one has gained lies at the heart of being able to promote one's skills and competences externally and for targeted self-development.

For other students the surfacing of the requirement to plan for their future career was the most valuable aspect of the module:

Identifying the things I need to do before I finish university to prepare me for making the most of my career.

That it's useful to look back and plan from your experiences, no matter how trivial they may seem.

Learning how important it was to plan for the future.

It [personal statement assignment 1] really made me think about my next steps in my future and career, which is vital. This is the only module at university which made me think about my aspirations in greater depth. This is crucial because you need direction in the future.

For others there was clear evidence that they had come to decisions or resolutions of uncertainty: 
The most useful thing I learned whilst doing this assignment [personal statement] was definitly finding out the skills, abilities, opportunities, and general information on becoming a magazine journalist. So now when I leave university I know exactly what type of journalist l'd like to be, what the salary is like etc so it was a very useful assignment in my opinion. As I can now take a realistic approach to the world of work.

By writing out and researching into 'where I want to be', it made me think about the things I want to do after university. It also helped me to figure out that I do want to complete Masters. [...].

And finally, for others there was clearly an affective outcome:

Establishing what my passions are and what I want to gain from life on planet earth.

I feel that learning more about the job market ingeneral has been very useful, as it has highlighted to me how hard it may be to be able to achieve the career I aspire to. This gives me more motivation to reach my goal.

As outlined above, the module employed a variety of pedagogical strategies which included self-assessment activities through the e-Portfolio package and an Activity-led learning approach (Wilson-Medhurst, 2008) for key parts of the delivery. Whilst engagement in these elements appeared to develop a shift in the reflective capacity of many students, some students struggled conceptually with the meta-cognitive nature of reflection, unable to identify developed skills or capabilities beyond descriptive accounts of often limited experiences. This reflects the findings of Orsini-Jones (2006) who proposed meta-cognition as a generic skill threshold in reference to the notion of threshold concept. The notion of threshold concepts was first introduced by Meyer and Land (2003) to characterise the idea that in certain disciplines there are concepts that 'represent a transformed way of understanding, or interpreting, or viewing something without which the learner cannot progress' (Meyer and Land, 2003, pp. 412-424). Threshold concepts are often likened to a portal or conceptual gateway in that they open up a new and previously inaccessible way of thinking about something. Such concepts may be transformative, irreversible and integrative in the way they change how people think in a discipline or perceive particular phenomena. 
The students undertaking this module were final year students and other interventions may be necessary which will be the subject of continuing research. Nevertheless all students reported some personal gains even if these were small shifts from, for example, what might be described as descriptive writing to descriptive reflection (Hatton and Smith, 1995) e.g. reporting increased confidence in a specific skill or surfacing the need to work on a particular skill area.

\section{Reviewing the research question}

So what does our appreciative feedback data tell us about the elements that support and encourage a reflective capacity?

Table 1 below summarises findings gathered from further analysis of the responses to the question '....what has been the most useful aspect of the module so far? And why?'. The analysis focussed on identifying any specific elements that students flagged up in their appreciative responses. This analysis was derived from the responses from the 25 (from a total of 48) students in the 2009/10 cohort who completed this question (data for this specific question is not available for the 2008/9 cohort).

Again, students typed their responses within the e-Portfolio environment and were not asked to spell check their responses. Hence, as above, minor slips on the keyboard are left as written, as are spelling errors.

The findings in Table 1 indicate that, as might be expected, different elements were appreciated by different learners within the 2009/10 cohort. However, the most frequently mentioned were the group activity or sub-elements within it, and the personal statement assignment 1 or sub-elements within it (in fact these two elements were intrinsically linked), as well as an appreciation of the module in its entirety. There is insufficient data here to make any more claim than this but it does point to elements of the module that were working well. 
Table 1. Module elements that students appreciated.

\begin{tabular}{|c|c|}
\hline Element & $\%$ of respondents \\
\hline $\begin{array}{l}\text { Team activity on the graduate job/destinations } \\
\text { market } \\
\text { E.g. 'The group task, as I learned good techniques off } \\
\text { of others and good places to look for jobs. It also } \\
\text { helped me to give more time to lokoing into } \\
\text { placements and how I could apply and opened my } \\
\text { eyes to new niche areas'. }\end{array}$ & $28 \%$ \\
\hline $\begin{array}{l}\text { Personal statement assignment } 1 \text { incorporating } \\
\text { self-assessment } \\
\text { E.g. 'Completing the self-assessment coursework as it } \\
\text { puts me in good stead to see where I stand'. }\end{array}$ & $24 \%$ \\
\hline $\begin{array}{l}\text { The module itself (feedback indicated various } \\
\text { elements linked to the module itself) } \\
\text { E.g. 'The module has helped me to begin looking at } \\
\text { what I can do once I have finished my degree, and has } \\
\text { also shown me how to organise my achievements, and } \\
\text { how I can use them as evidence when applying for } \\
\text { jobs in the future'. }\end{array}$ & $24 \%$ \\
\hline $\begin{array}{l}\text { A specific activity ( } 3 \text { were mentioned - Personal } \\
\text { SWOT analysis; 'a structured breakdown of the } \\
\text { way a business thinks about the progress of its } \\
\text { employees'; Action Planning lecture) } \\
\text { E.g. 'Conducting the SWOT analysis helped me } \\
\text { understand my strengths and weaknesses - very } \\
\text { useful for when I apply for a job'. }\end{array}$ & $12 \%$ \\
\hline $\begin{array}{l}\text { Reflective process itself } \\
\text { E.g. 'Learning how to reflect on what I have done and } \\
\text { evidencing my progress'. }\end{array}$ & $12 \%$ \\
\hline Total & $100 \%$ \\
\hline
\end{tabular}


Further analysis of the above 25 feedback statements revealed that they evidenced engagement with one or more of Crites' $(1976$; 1978) career choice processes in all except two (out of 25) responses. In some instances the appreciative feedback statement revealed engagement with more than one career choice process, for example:

I managed to explore myself in terms of qualities such as finding out what kind of team player type I am and I have developed confindence in applying for jobs after finishing my degree. I also developed confidence and skills in making presentations.

The above feedback statement suggested engagement with both 'accurate self-appraisal' and 'making plans for the future' career choice processes. Thus from 25 statements, 52 codes were allocated. The findings are summarised in table 2.

Table 2. Career choice processes evident in appreciative feedback.

\begin{tabular}{|c|c|}
\hline Career choice process & $\%$ of allocated codes \\
\hline $\begin{array}{l}\text { Accurate self-appraisal } \\
\text { E.g. 'Making me see my strengths and weaknesses } \\
\text { much clearer. It will help me a lot because I can } \\
\text { now correct my weaknesses and build on my } \\
\text { strengths in time for work in the real world'. }\end{array}$ & $29 \%$ \\
\hline $\begin{array}{l}\text { Gathering occupational information } \\
\text { E.g. 'To have a structured breakdown of the way a } \\
\text { business thinks about the progress of its } \\
\text { employees, and to know a bit better what will be } \\
\text { expected of me'. }\end{array}$ & $15 \%$ \\
\hline $\begin{array}{l}\text { Goal selection } \\
\text { E.g. 'I have found this module useful as it has made } \\
\text { me think about where I want to be by the end of my } \\
\text { degree, I now know that I wish to further my studies } \\
\text { with a MA degree'. }\end{array}$ & $12 \%$ \\
\hline $\begin{array}{l}\text { Making plans for the future } \\
\text { E.g. 'It [the module] has triggered me to think about } \\
\text { my future in more detail and carry out more } \\
\text { research into possible areas I could work in'. }\end{array}$ & $27 \%$ \\
\hline
\end{tabular}




\begin{tabular}{|l|l|}
\hline $\begin{array}{l}\text { Problem solving } \\
\text { E.g. 'The most useful aspect has been in identifying } \\
\text { my weaknesses and looking at methods of } \\
\text { improving them'. }\end{array}$ & $13 \%$ \\
\hline $\begin{array}{l}\text { Other - specific skills (reflective writing; } \\
\text { presentation skills) }\end{array}$ & $4 \%$ \\
$\begin{array}{l}\text { E.g. 'I have learnt to write reflectively, and the ways } \\
\text { in which to do so. I can also use pebblepad } \\
\text { properly'. }\end{array}$ & \\
\hline
\end{tabular}

Table 2 and the quotes in the section above indicate that students were engaging in reflective activity around personal and career development. Taken together with Table 1, the authors suggest this evidence indicates the module design itself supported this reflection, but that the interdisciplinary group activity linked to personal statement assignment 1 was particularly supportive within this design. Support for the claim of the success of the module in supporting the reflective capacity of learners also comes from external examiners' feedback for the 2009/10 session, as well as the module pass rates for the $2009 / 10$ session which was $96 \%$ of registered students.

In their general comments on the nature of the task and student performance in 2009/10 the external examiner's comments included the following:

This was a very interesting range of self-reflective passages oriented towards the students' future career plans. I particularly liked the idea of encouraging the students to link their skills development at university to the needs of their potential employers in the future. It helps them to think about transferable skills and continuous professional development/lifelong learning. There were some really good pieces of work which show the students are readily able to analyse themselves and their skills performance in relation to future needs.

Below is an exploration of the key features of two of the key elements that seemed to work - the interdisciplinary group activity and personal statement assignment 1. 


\section{Key features of the group activity and personal statement assignment 1}

1) Group activity on the graduate job/destinations market:

- Teams of six (or exceptionally five or seven) drawn from a range of disciplines.

- Each team member researches different graduate destination.

- Activity design requires them to pool information and analyse to complete successfully.

- Team presentations to rest of cohort.

- Formatively assessed (no marks, formative feedback only using pre-issued feedback grid).

- Experience feeds into personal statement assignment 1.

The interdisciplinary composition of the group work exercises, combined with presentations to the whole group, seemed to allow an appreciation of the skills and attributes developed within the students' own disciplines which might not have been previously apparent to them. The interdisciplinary possibilities are a unique feature of the Add+vantage scheme at Coventry which brings together learners from a wide range of disciplines. The authors suggest this interdisciplinary composition facilitates reflection by encouraging a 'standing back' and seeing one's own discipline and development through others' eyes.

2) Personal statement assignment 1:

- Experience from the group activity feeds into personal statement assignment 1 with the aid of the scaffolding questions below.

- Scaffolding questions: Where am I now? Where do I want to be? Where do I need to be? (Kumar, 2007).

- E-Portfolio scaffolding, particularly for assembling and presenting evidence related to self-reflection and action planning.

- Self-assessment of personal statement submission against assignment marking criteria (before tutor feedback and mark returned) - this was e-Portfolio enabled.

The reviewing of one's own submission is an example of an embedded activity explicitly designed to support the reflective process. 


\section{Conclusions and areas for further research}

This research highlights that students do appreciate the module elements designed to support them in planning and preparing for 'transition out' of university and in career choice processes. Key elements of the module which encouraged and supported the reflective capacity of students were the personal statement first assignment linked to interdisciplinary group work, including embedded and e-Portfolio enabled activities which scaffold the reflective process. For example, the opportunity for students to review their first assignment was an integral part of the learning in the first assignment and this process was facilitated and managed within the e-Portfolio environment.

A focus for further work will be to further examine the benefits of inter-disciplinary group work. This is an important feature of the scheme at Coventry which brings together groups of learners from a wide range of disciplines. The interdisciplinary composition of the group work exercises seemed to allow an appreciation of the skills and attributes developed within their own discipline which might not have been previously apparent to students. This seemed to come through discussions relating to the skills and attributes of their peers who came from unrelated disciplines. Subsequently, the scaffolding questions in the personal statement assignment then supported the students in reflecting on their learning from this experience.

A further area for research is whether enhancements to the module elements, including the interdisciplinary group work, would help develop the reflective capacity of those learners who, despite the interventions outlined in this paper, still struggle conceptually with the meta-cognitive nature of reflection. For example, an appreciative peer-review of other students' personal statement submissions might be one enhancement that could be investigated and is consistent with enhancements suggested by the external examiner. This would further expose students to the learning and vantage points of those who come from different disciplines and backgrounds, and hence have the potential to facilitate reflection. 


\section{Acknowledgement}

This paper is an outcome of the National Action Research Network on researching and evaluating Personal Development Planning and e-Portfolio practice project (2007-2010). The project was led by the University of Bolton in association with the University of Worcester and Centre for Recording Achievement, and in national collaboration with the University of Bedfordshire, Bournemouth University and University of Bradford. The project was funded by the Higher Education Academy, National Teaching Fellowship Project strand. More details about the project can be found at: http://www.recordingachievement.org/research/narn-tree.html.

\section{References}

Ada, W.W. (2010) 'Computer supported collaborative learning and critical reflection: a case study of fashion consumerism', Interdisciplinary Journal of E-Learning and Learning Objects, 6, pp. 87-102 [Online]. Available at: http://ijello.org/Volume6//JELLOv6p087-102Ma686.pdf (Accessed: 9 October 2010).

Andrew, D., Green, M., Pheiffer, G. and Holley, D. (2002) 'A critical review of the use of the concept of reflection in Higher Education', BEST Conference. Edinburgh 8-10 April.

Bandura, A. (1997) Self-efficacy: the exercise of control. New York: W.H. Freeman.

Brennan J. and Shah T. (2003) Access to what? Converting educational opportunity into employment opportunity. Final report. London: The Centre for Higher Education Research and Information.

Cooperrider, D.L., Whitney, D. and Stavros, J.M. (2008) Appreciative inquiry handbook. 2nd edn. Brunswick, OH: Crown Custom Publishing Inc.

Cousins, G. (2009) Researching learning in higher education. New York: Routledge. 
Crites, J.O. (1976) 'A comprehensive model of career development in early adulthood', Journal of Vocational Behaviour, 9, pp.105-118.

Crites, J.O. (1978) The career maturity inventory: administration and use manual. 2nd edn. Monterey, California: McGraw Hill.

Hatton, N. and Smith, D. (1995) 'Reflection in teacher education - towards definition and implementation', Teaching and Teacher Education, 11(1), pp. 33-49.

Kolb D.A. (1984) Experiential learning: experience as the source of learning and development. New Jersey: Prentice-Hall Inc. Englewood Cliffs.

Kumar, A. (2007) Personal, academic and career development in higher education: SOARing to success. London and New York: Routledge Taylor and Francis Group.

Meyer, J.H.F. and Land, R. (2003) 'Threshold concepts and troublesome knowledge: linkages to ways of thinking and practising within the disciplines', in Rust, C. (ed.) 10th international symposium on improving student learning: theory and practice 10 years on. Oxford: Oxford Centre for Staff and Learning Development, pp. 412424.

Moon, J. (1999) Reflection in learning and professional development. London: Kogan Page.

Moon, J. (2001) PDP working paper 4: reflection in higher education learning. LTSN Generic Centre. Available at: http://www.york.ac.uk/admin/hr/training/gtu/students/resources/pgwt/reflectivepracti ce.pdf (Accessed: 18 May 2010).

Orsini-Jones, M. (2006) 'Identifying troublesome concepts and helping undergraduates with crossing grammar threshold concepts via assessed collaborative group work', Threshold Concepts within the Disciplines Symposium. Glasgow (Durham University/Staffordshire University/University of Strathclyde) 30 August - 1 September, pp. 119-129. 
Orsini-Jones, M. and Jones, D. (2007) 'Supporting collaborative grammar learning via a Virtual Learning Environment (VLE): a case study from Coventry University, Arts and Humanities in Higher Education, 6(1), pp. 90-106.

QAA (2001) QAA Guidelines for HE progress files. Quality Assurance Agency. Available at:

http://www.qaa.ac.uk/academicinfrastructure/progressFiles/guidelines/progfile2001. pdf (Accessed: 13 July 2010).

Stefani, L., Mason, R. and Pegler, C. (2007) The educational potential of e-Portfolios: supporting personal development and reflective learning. London: Routledge.

Strivens, J. (2007) A survey of ePDP and e-Portfolio practice in UK higher education. York: Higher Education Academy.

Wilson-Medhurst, S. (2005a) 'Using assessment to support employability awareness and development', Investigations in University Teaching and Learning, 3(1) Autumn, pp.72-79. London Metropolitan University, ISSN 1740-5106.

Wilson-Medhurst, S. (2005b) 'Supporting student development using reflective writing', Investigations in University Teaching and Learning, 2(2) Spring, pp. 89-92. London Metropolitan University, ISSN 1740-5106.

Wilson-Medhurst, S. (2008) 'Towards sustainable activity led learning innovations in teaching, learning and assessment', Proceedings of Engineering Education 2008 International Conference on Innovation, Good Practice and Research in Engineering Education: EE2008. Loughborough University, 14-16 July. Available at: http://www.engsc.ac.uk/downloads/scholarart/ee2008/p008-wilson-medhurst.pdf [Accessed: 10 September 2009).

Yancey, K. B. (2009) Electronic portfolios a decade into the twenty-first century: what we know, what we need to know. Peer Review. Available at: http://findarticles.com/p/articles/mi qa4115/is 200901/ai n31964582/ (Accessed: 24 July 2009). 
Yorke M., Knight P. and contributors (2003) The undergraduate curriculum and employability: a briefing paper. Available at: http://www.heacademy.ac.uk/resources/detail/resource database/id248 The Unde rgraduate Curriculum and Employability (Accessed: 18 May 2010).

\section{Author details}

Sarah Wilson-Medhurst is a teaching practitioner, educational developer and researcher leading pedagogic innovation, development and adoption within the Faculty of Engineering and Computing at Coventry University. Her focus is on student-centred and active learning approaches. From 2007-2010 she was a leading member of two major research and evaluation initiatives in relation to PDP and e-Portfolio practice: Cohort IV of the Inter/national Coalition for E-Portfolio Research, and the NTFS National Action Research Network (NARN).

Andrew Turner is Programme Manager for Teaching and Learning in Organisational Learning and Development at Coventry University where he leads the Postgraduate programmes in Higher Education Professional Practice. He was formerly in the Centre for the Study of Higher Education (CSHE) at Coventry University where he led the iPED Pedagogical Research Network and the team of Teaching Development Fellows. In addition, he chaired the University Personal Development Planning working group to develop an institutional PDP policy. 